\title{
Gênero e Serviço Social: uma análise a partir do paradigma indiciário*
}

\section{Gender and social work: an analysis from the indiciary paradigm}

\author{
Ana Lole \\ Doutora em Serviço Social pela PUC-Rio/RJ, Brasil, \\ assistente social e mestre em Política Social pela UFF, Brasil. \\ analole@gmail.com
}

Resumo: Neste artigo apresentamos ressonâncias dos estudos de gênero no Serviço Social valendo-nos das contribuições do paradigma indiciário (Ginzburg, 1990). Sustentamos que, ao longo do tempo, recorrências de análises de gênero na produção profissional, aparentemente desconexas, revelam uma presença do tema no Serviço Social que se intensificou nos últimos anos. Nesse sentido, examinamos as estratégias de formação profissional na perspectiva da incorporação do gênero na atualidade.

Palavras-chave: Gênero. Serviço Social. Paradigma indiciário. Formação profissional.
Abstract: In this paper we present resonances of gender studies in Social Work through the contributions of the indiciary paradigm (Ginzburg, 1990). We support that, over time, recurrences of gender analysis in professional production, seemingly disconnected, reveal this subject's presence in Social Work that has intensified in recent years. In that sense, we examine the professional training strategies in the incorporation of the gender perspective today.

Keywords: Gender. Social Work. Indiciary paradigm. Professional qualification.

\section{Introdução}

om a inspiração em Mitos, emblemas, sinais (1990) do historiador italiano Carlo Ginzburg sobre o paradigma indiciário, ${ }^{1}$ examinaremos sinais da presença do debate de gênero no Serviço Social. O paradigma indiciário constitui uma forma de juntar elementos/dados para realizar a apreensão de um

* Este artigo é resultado da pesquisa da tese de doutorado; para maior aprofundamento ver: Lole (2014).

1. Para o historiador, o "paradigma indiciário" ou "método indiciário" parte de uma comparação com as técnicas aplicadas por Morelli, Sherlock Holmes e Freud, referindo-se de maneira relevante no exame de pequenos indícios ou pistas. 
fenômeno cujos registros ainda não são consistentes, devendo ser tomados enquanto indícios, pistas ou sinais. $\mathrm{O}$ autor considera que há por trás dessa espécie de fragmento toda uma explicação mais abrangente, de modo que "pistas talvez infinitesimais permitem captar uma realidade mais profunda, de outra forma inatingível" (Ginzburg, 1990, p. 150). O historiador italiano situa sua proposta sobre o indiciarismo no bojo dos incômodos de modelos epistemológicos que se contrapõem entre "racionalismo" e "irracionalismo", para enfatizar a existência silenciosa, nas ciências humanas, de um modelo que tem passado despercebido.

Após descrever uma série de conhecimentos desenvolvidos com base nos indícios e sinais em áreas como a criminologia, Ginzburg (1990, p. 177) afirma:

[...] o mesmo paradigma indiciário usado para elaborar formas de controle social sempre mais sutis e minuciosas pode se converter num instrumento para dissolver as névoas da ideologia que, cada vez mais, obscurecem uma estrutura social como a do capitalismo maduro. Se as pretensões de conhecimento sistemático mostram-se cada vez mais como veleidades, nem por isso a ideia de totalidade deve ser abandonada. Pelo contrário: a existência de uma profunda conexão que explica os fenômenos superficiais é reforçada no próprio momento em que se afirma que um conhecimento direto de tal conexão não é possível. Se a realidade é opaca, existem zonas privilegiadas — sinais, indícios — que permitem decifrá-la. (Grifos nossos)

A relevância do paradigma indiciário para nossa análise dos estudos de gênero no âmbito profissional do Serviço Social se explica pela sua capacidade de suscitar novas descobertas num ambiente povoado por referências muito consagradas como viés explicativo de todas as facetas da realidade, como observamos ocorrer nas últimas décadas no âmbito da profissão. Neste sentido, temos que estar atentos para os "achados" que "são frutos do acaso, e não da curiosidade deliberada. Surge em algum momento da pesquisa onde a sensação é de ter encontrado uma pista relevante e ao mesmo tempo a consciência aguda da ignorância sobre o que é ou significa" (Ginzburg, 2004, p. 11).

Ainda que nosso interesse de pesquisa buscasse desvelar a apreensão dos estudos de gênero no Serviço Social, de início partimos de uma concepção que acentuava a pouca visibilidade desses trabalhos no âmbito profissional. ${ }^{2}$ De certo

2. É importante lembrar os esforços de Suely Gomes Costa e Marlise Vinagre, que, entre outras iniciativas, foram pioneiras na criação nos anos 1980 de uma disciplina de gênero na Escola de Serviço Social da UFF. 
modo, fomos surpreendidas no curso da pesquisa com eventos dispersos que nos levaram a reposicionar a análise no sentido de valorizar as evidências sobre a existência de um diálogo crescente do Serviço Social com essa área de estudos. Essas pistas referem-se, por exemplo, ao crescimento do interesse pela questão em situações como, por exemplo, da chamada de artigos para um número sobre gênero da revista Temporalis, ${ }^{3}$ periódico vinculado à Abepss (Associação Brasileira de Ensino e Pesquisa em Serviço Social). Como indica o editorial ${ }^{4}$ da revista, "na atual gestão, a submissão de artigos dessa temática foi a que mais mobilizou, até então, o envio de trabalhos para publicação", tendo sido computados 122 trabalhos, não considerando aqueles que se autodefiniram na temática, mas que foram eliminados numa primeira avaliação. Isto levou o comitê à decisão de dedicar o número seguinte do periódico à mesma temática. Além desse evento, verifica-se também demanda crescente por pesquisas sobre a temática do gênero no âmbito das pós-graduações stricto sensu em Serviço Social, cujas áreas de concentração são menos permeáveis a esses estudos, ${ }^{5}$ para citar apenas algumas das pistas recentemente encontradas.

Neste artigo, propomo-nos a mapear as incidências da análise de gênero no Serviço Social, enfatizando o processo formativo nas universidades e localizando os elementos teóricos profissionais que colidem e/ou possibilitam a abertura ao debate de gênero.

Nossa pesquisa considera que apesar de o debate de gênero ser crescentemente incorporado pelo Serviço Social na atualidade, ainda temos alguns sinais no interior da profissão de uma "subalternidade" dos estudos de gênero, especialmente no plano dos currículos de Serviço Social. Então a intenção, neste artigo, é analisar as expressões e os efeitos atuais do gênero na profissão através de material empírico no âmbito da formação profissional, que é articulada pelas Diretrizes

\footnotetext{
Ainda nessa universidade, a criação do Programa de Estudos Pós-Graduados em Política Social, com ênfase em pesquisas na área de gênero no início dos anos 2000; grupo de estudos de gênero formado por professores da Escola de Serviço Social da UFRJ, com a assessoria de Heleieth Saffioti; as pesquisas de professores da UERJ nos anos 1990, que levaram à criação de um Programa de Estudos e Pesquisas na área de gênero e à introdução no currículo da época de uma disciplina na graduação. Nos anos 1980, a UFRJ foi pioneira na oferta de campo de estágio supervisionado em Delegacias Especializadas de Atendimento à Mulher (Deam's), além de uma disciplina eletiva sobre a matéria.
}

3. Temporalis, jan.jun. 2014.

4. Oliveira, Moreira e Gurgel, jan./jun. 2014, p. 9-10.

5. Indício observado durante a visita aos campos, ou seja, nas IES pesquisadas. 
Curriculares, o currículo das unidades de ensino e seu projeto político-pedagógico, bem como o Código de Ética Profissional de 1993, o conjunto CFESS/Cress ${ }^{6}$ e a Abepss. Nesse sentido, consideramos a hipótese de que o tema passa progressivamente a integrar as estratégias hegemônicas na profissão.

Os indícios e as pistas das considerações do gênero, aparentemente desconectados, mostram uma presença do tema na profissão. Aventamos que longe de se constituírem fragmentos desconexos, remetem a um plano de análise mais amplo que busca elaborar respostas ao conjunto de problemas apresentados na sociedade contemporânea. Assim, as pistas do interesse pelo debate de gênero no Serviço Social revelariam peças importantes no adensamento das lutas contra-hegemônicas a serem fortalecidas no âmbito da sociedade e da profissão. Com base na pesquisa realizada, nosso esforço será buscar coerência nesses indícios e pistas como zonas privilegiadas que remetem a uma perspectiva de compreensão da totalidade do fenômeno.

\section{Os indícios de gênero no currículo de Serviço Social}

Cumpre deixar claro que a análise de documentos, longe de buscar evidenciar uma realidade empírica ou descrever o que ocorre na prática, permite mostrar os discursos e narrativas que formulam determinada compreensão da profissão e, especialmente para os propósitos de nosso trabalho, ressaltam as construções teóricas produzidas e aquelas que são apartadas no jogo das definições do trabalho e da formação profissional. No caso dos currículos, sabemos que existem inúmeras táticas, resistências e embates teóricos que têm lugar no cotidiano das escolas de Serviço Social. Esses cenários formulam brechas e possibilidades para outras linguagens no campo das teorias críticas ou não, os quais ultrapassam as formulações postas pelos documentos institucionais. ${ }^{7}$

Nossa pesquisa foi desenvolvida junto às escolas/departamentos de Serviço Social de quatro instituições de ensino superior (IES) no estado do Rio de Janeiro:

\footnotetext{
6. CFESS - Conselho Federal de Serviço Social; Cress - Conselho Regional de Serviço Social.

7. Jurjo Torres Santomé, pesquisador espanhol, tem discutido no âmbito da educação as teorias reprodutivistas que não conseguem apreender os espaços e momentos das resistências criadoras e libertadoras nas instituições. A esse processo deu o nome de "currículo oculto". Para aprofundamento, consultar Santomé, 2005.
} 
Pontifícia Universidade Católica do Rio de Janeiro (PUC-Rio), curso criado em 1937; Universidade do Estado do Rio de Janeiro (UERJ), curso criado em 1944; Universidade Federal Fluminense (UFF), curso criado em 1945; Universidade Federal do Rio de Janeiro (UFRJ), curso criado em 1940.

Solicitamos das referidas IES o currículo pleno e a grade curricular referentes ao período compreendido entre 1996 e 2013. O período com início em 1996 se justifica porque naquele ano ocorreu a formulação das Diretrizes Curriculares da Abepss. Solicitamos também os programas das disciplinas que abordassem a perspectiva de gênero, se possível a partir de 2009, caso houvesse. Desta forma, nos debruçaríamos sobre um material referente aos últimos cinco anos. Cumpre destacar que buscamos visualizar nas grades curriculares não apenas disciplinas que possuíam no seu título a palavra "gênero", mas aquelas que pudessem guardar inter-relações com o debate, como, por exemplo, as disciplinas sobre família.

A escolha pela pesquisa nesses espaços deve-se à representatividade política que essas instituições de ensino possuem historicamente na formação do assistente social, por oferecerem cursos de pós-graduação stricto sensu na área de Serviço Social e por se localizarem no estado do Rio de Janeiro.

Cabe alertar que não foi possível obter todos os programas do período estabelecido. As IES pesquisadas não possuíam os programas referentes a todos os semestres solicitados. Em algumas, inclusive, só havia um programa referente a cada disciplina.

Quadro 1 - Programas das disciplinas com abordagem de gênero segundo IES

\begin{tabular}{|c|c|c|c|c|}
\hline Instituição & PUC-Rio & UERJ & UFF & UFRJ \\
\hline Programas das disciplinas (total) & 1 & 20 & 22 & 6 \\
\hline
\end{tabular}

Fonte: Coleta de Dados da Pesquisa, 2013.

No que tange à observação sobre a influência das Diretrizes nos currículos das unidades de ensino estudadas, constatamos que o Departamento de Serviço Social (DSS) da PUC-Rio realizou sua revisão curricular em 2002, com o desafio de analisar e incorporar ao seu Projeto Político-Pedagógico as orientações da Abepss que não estivessem contempladas no currículo em vigência. Cabe ressaltar que o curso de graduação em Serviço Social dessa unidade tem sua origem na Escola de 
Serviço Social do Instituto Social, criada em 1937. Na história do Serviço Social brasileiro, é o segundo curso de graduação que surge no país. O primeiro foi o da PUC-SP, criado em 1936.

O DSS/PUC-Rio baseia-se nas Diretrizes Curriculares e, tendo em vista as particularidades de essa unidade de ensino situar-se numa universidade de natureza católica, a grade curricular do curso de graduação de Serviço Social da PUC-Rio é composta por um conjunto de disciplinas organizadas em três núcleos específicos: o de formação básica, o de formação geral e cultural e o de formação profissional.

Considerando a preocupação da unidade de ensino em incorporar a proposta das Diretrizes, é necessário destacar, no entanto, que não ocorre uma ruptura com a concepção original do currículo, na medida em que o esforço tem o propósito de agregar as propostas. Todavia, se temos por referência o sentido contido nas Diretrizes, o qual aponta para o projeto profissional semeado na ruptura, a inspiração de base católica que aparece no currículo mostra concepções profissionais em disputa. Cabe lembrar que a experiência do currículo não se resume à grade curricular, mas se operacionaliza em atos, rotinas, processos cotidianos que envolvem sujeitos variados que vão construindo sentidos inesperados.

Em entrevista concedida a Silva e Delboni (2012), Jurjo Torres Santomé aborda as ocorrências em sala de aula na construção da experiência formativa, que estão além dos manuais prescritos, articulando-se com as experiências mais amplas dos sujeitos envolvidos:

Todos podemos lembrar, como professoras e professores, com forte compromisso político e social, que nos ajudavam a ver aquelas realidades que os manuais escolares e os meios de comunicação tratavam de ocultar ou de deformar; como, em debates que se abriam na sala de aula, outras alunas e alunos ofereciam dados com muito mais poder explicativo do que, inclusive, os que o professor nos dava. (Silva e Delboni, 2012, p. 283)

No que diz respeito à revisão curricular do DSS/PUC-Rio, quanto às possibilidades de abordagem do gênero na formação profissional, temos que a grade curricular apresenta uma lógica em que os eixos centrais são teoria, metodologia e história, tratados de forma dicotomizada. A questão do gênero não é contemplada na visualização das disciplinas. 
A Faculdade de Serviço Social (FSS) da UERJ implementou a revisão de seu currículo em 1993, mediante um processo que se desdobrou ao longo dos anos de 1989 a 1992. Nesse período, não apenas realizou-se a crítica ao currículo anteriormente em vigor, como também foi propiciada uma dinâmica que envolveu o aprimoramento dos docentes a partir da inserção e da participação deles em todas as etapas, além de socialização com movimentos de revisão curricular de outras unidades de ensino. Cumpre ressaltar que após as Diretrizes da Abepss, a unidade não realizou revisão curricular, muito embora tenha participado ativamente através da produção e do envolvimento de seus professores nos debates à época da sua construção. ${ }^{8}$

Com base no currículo da FSS/UERJ, destacamos a importância conferida a processos investigativos assim como a uma formação que propicie ao graduando o contato com as dinâmicas da realidade contemporânea, o que implicaria uma atenção constante aos processos de renovação do debate profissional. De acordo com a grade curricular, isso seria assegurado com as estratégias de

atualizar o curso com temas e polêmicas contemporâneas expressas em novas conjunturas através das disciplinas eletivas "Tópicos Especiais", de modo a atravessar o currículo com polêmicas postas pelo avanço da produção e pesquisa na faculdade. E, ainda, através do direito do aluno a inscrição em disciplinas eletivas de outras unidades, visa-se estimular a maior amplitude da formação e experimentação pelos alunos no tocante à interlocução com outras áreas acadêmicas. (UERJ, 1992, p. 5; grifos nossos)

O projeto político-pedagógico da FSS/UERJ define o trabalho profissional a partir da inserção dos assistentes sociais nas "tramas sócio-institucionais, que configuram o campo das políticas sociais públicas e privadas" (UERJ, 1992, p. 4). Dessa forma, elege a política social como o eixo aglutinador da formação, em consonância com o debate produzido em torno das Diretrizes. As disciplinas estão organizadas em três grupos fundamentais: Construções Teórico-Metodológicas do Serviço Social, Processo de Trabalho do Serviço Social e Políticas Sociais.

8. Cabe ressaltar que a FSS da UERJ aprovou e está iniciando sua revisão curricular no segundo semestre de 2015 . 
Do ponto de vista do debate de gênero, observamos que não há menção aos estudos nessa área como parte constitutiva dos eixos que integram a formação profissional no documento que apresenta o projeto curricular dessa unidade de ensino. Assim, tem por objetivo:

Proporcionar o conhecimento da dinâmica do mercado de trabalho, da emergência e institucionalização das demandas sociais, das respostas e construções teórico-práticas da profissão, tendo como referência o significado sociopolítico e a efetiva inserção do Serviço Social no contexto da reprodução social. (UERJ, 1992, p. 4)

Desse modo, o currículo afina-se com o projeto profissional crítico que define o Serviço Social na perspectiva da teoria social marxista, conferindo distinção ao trabalho dos assistentes sociais no âmbito das políticas sociais como eixo central da formação.

A Escola de Serviço Social (ESS) da UFF realizou, em 1999, a reforma curricular, que buscou uma nova organização do currículo a partir das Diretrizes Curriculares do Ministério da Educação (MEC) e com assimilação das elaborações da Abepss. Contudo, em maio de 2010 realizou um ajuste curricular ao reconhecer que

as condições adversas é condição para estabelecer um projeto de ajuste curricular. Entendê-las é condição para não sucumbir a elas. Após quase dez anos de implantação do currículo, já temos condições de avaliá-lo. Nossa compreensão é de que o projeto de formação nele contido está atual e possibilita a formação de profissionais críticos e competentes nos níveis teórico-metodológico, ético-político e técnico-operativo. A partir deste patamar, avaliamos as mudanças necessárias, em especial pelo fato de que as propostas de composição de outras atividades que deveriam interagir diretamente com as disciplinas não se efetivaram. Além disso, verificamos que algumas disciplinas podem ser condensadas, introduzidas e, outras, extintas, além de ser necessária a reformulação do conteúdo de algumas, o que visa aperfeiçoar tão somente o currículo construído no início dos anos 2000. (UFF, 2010, p. 1-2)

Nesse sentido, fica evidente que a mudança é de reordenamento, mais do que de produção de uma ruptura significativa com os rumos da formação nessa unidade de ensino. De acordo com o Projeto Político-Pedagógico da instituição, a ESS/UFF foi a primeira unidade de ensino a implantar um novo currículo de 
acordo com as Diretrizes da Abepss. Em sua proposta, a Escola reafirma os princípios que norteiam as Diretrizes Curriculares, com base nos aspectos éticos e políticos plasmados no Código de Ética de 1993, explicitando "a mesma direção social, que se expressa em um profundo diálogo com a tradição marxista, garantindo-se, é claro, o respeito às diferenças e à pluralidade no pensamento científico" (UFF, 2010, p. 4).

O projeto pedagógico profissional do currículo da ESS/UFF aponta a centralidade da "questão social" estruturante do trabalho do assistente social, enfatizando as políticas sociais nas quais se articula a intervenção da categoria. Retoma, na configuração dos núcleos que congregam suas disciplinas, a mesma estrutura apresentada no documento da Abepss (1996), destacando a importância da articulação com a realidade social e a interdisciplinaridade como elementos fundamentais da formação dos alunos. No conjunto da proposta não se explicitam objetivos que se articulem com o potencial analítico dos estudos de gênero, como observamos nas proposições das demais unidades de ensino anteriormente analisadas.

O curso de Serviço Social oferecido pela Escola de Serviço Social (ESS) da UFRJ tem o seu currículo vigente estruturado conforme a revisão curricular aprovada em 2001. Cumpre destacar que ele também reafirma os princípios norteadores das Diretrizes Curriculares da Abepss e do Código de Ética de 1993. Todavia, a ESS/UFRJ traz um diferencial em relação às demais unidades e àquelas Diretrizes ao apontar dentre os princípios do seu projeto pedagógico a questão de classe, gênero e etnia explicitamente no cenário da superação da atual ordem societária burguesa:

O projeto pedagógico da ESS/UFRJ, sintonizado com o projeto ético político hegemônico do Serviço Social brasileiro, tem por princípios norteadores os valores explicitados na fundamentação do Código de Ética Profissional do Assistente Social: o reconhecimento da liberdade como valor ético central e das demandas políticas a ela inerentes (autonomia, emancipação e pleno desenvolvimento dos indivíduos sociais), com a defesa intransigente dos direitos humanos e recusa do arbítrio e do autoritarismo; ampliação e consolidação da cidadania; defesa do aprofundamento da democracia; posicionamento em favor da equidade e da justiça social; garantia do pluralismo e opção por um projeto profissional vinculado ao processo de construção de uma nova ordem societária, sem dominação-exploração de classe, etnia e gênero. (UFRJ, 2001, p. 6) 
O projeto indica a interdisciplinaridade e a pesquisa, assim como a centralidade da política social na articulação do perfil profissional que se deseja formar (UFRJ, 2001). Para tanto, articula três áreas fundamentais de conhecimento: fundamentos teórico-metodológicos da vida social; fundamentos da formação social brasileira; fundamentos da ação profissional. No que tange à formação social brasileira, merece destaque a compreensão de que esta envolve conteúdos, como poder local, questão fundiária e urbana, direitos humanos e sociais, "questão social" e conhecimentos relativos a identidades culturais e questão de gênero (UFRJ, 2001). Torna-se, assim, uma proposta formativa que incorpora a análise de gênero no quadro interpretativo da dinâmica da sociedade capitalista e das formas de superação desta.

Em linhas gerais, podemos resumir que do ponto de vista da articulação com a teoria social marxista, apenas o DSS/PUC-Rio não aponta um direcionamento para essa perspectiva, apresentando um currículo que mantém a estrutura formal dos cursos pré-reforma curricular dos anos 1980. Se focalizarmos a questão de gênero como um dos eixos estruturadores da formação profissional, apenas a ESS/ UFRJ aponta claramente essa compreensão, seja nos seus princípios norteadores, seja na definição do conteúdo de um dos núcleos que agregam os conhecimentos veiculados no curso.

Os cursos de Serviço Social das referidas IES possuem a seguinte estrutura, no que tange à duração:

Quadro 2 - Duração do curso de Serviço Social segundo IES

\begin{tabular}{|c|c|c|c|c|}
\hline Instituição & PUC-Rio & UERJ & UFF & UFRJ \\
\hline Semestres & 8 & 10 & $\begin{array}{c}10 \text { (diurno e } \\
\text { noturno) }\end{array}$ & $\begin{array}{c}8 \text { (diurno) } \\
10 \text { (noturno) }\end{array}$ \\
\hline
\end{tabular}

Fonte: Coleta de Dados da Pesquisa, 2013.

Cabe ressaltar que antes do ajuste de 2010 o curso de Serviço Social da ESS/ UFF tinha nove semestres letivos.

Focalizamos as disciplinas de estágio em Serviço Social, a seguir, na medida em que elas são fundamentais para a apreensão das dinâmicas da sociedade no âmbito da formação dos alunos. Nelas se formulam as conexões com os desafios 
da experiência social e podem ser executadas as mediações teórico-práticas, das quais participam de forma relevante as compreensões sob a ótica de gênero. As disciplinas de estágio são consideradas pelas Diretrizes da Abepss de 1996 como atividades indispensáveis integradoras do currículo: "É uma atividade curricular obrigatória que se configura a partir da inserção do aluno no espaço socioinstitucional, objetivando capacitá-lo para o exercício do trabalho profissional, o que pressupõe supervisão sistemática" (Abepss, 1996, p. 19). Os currículos das unidades de ensino estudadas apresentam a seguinte configuração quanto ao estágio: o DSS/PUC-Rio oferece dois períodos de estágios; a FSS/UERJ e a ESS/UFRJ possuem quatro períodos, e a ESS/UFF, três.

Quadro 3 - Período do estágio obrigatório em Serviço Social segundo IES

\begin{tabular}{|c|c|c|c|c|}
\hline Instituição & PUC-Rio & UERJ & UFF & UFRJ \\
\hline Períodos & $7^{\circ}$ e $8^{\circ}$ & $6^{\circ}, 7^{\circ}, 8^{\circ}$ e $9^{\circ}$ & $\begin{array}{c}5^{\circ}, 6^{\circ} \text { e } 7^{\circ} \\
(\text { diurno e noturno) }\end{array}$ & $\begin{array}{c}4^{\circ}, 5^{\circ}, 6^{\circ} \text { e } 7^{\circ} \\
(\text { diurno) } \\
6^{\circ}, 7^{\circ}, 8^{\circ} \text { e } 9^{\circ} \\
\text { (noturno) }\end{array}$ \\
\hline
\end{tabular}

Fonte: Coleta de Dados da Pesquisa, 2013.

É preciso assinalar o estatuto que essa atividade tem no âmbito da formação profissional, na medida em que consideramos a hipótese de que os espaços sócio-ocupacionais apontam cenários nos quais a leitura dos estudos de gênero se faz indispensável à formulação de um projeto de intervenção consistente. É no cotidiano da atuação profissional que se verificam os desafios ao conhecimento e a necessidade de um método investigativo e interventivo que considere a experiência produzida individual e coletivamente pelos sujeitos.

Nesse sentido, um elemento marcante tem sido a defesa de que esse tipo de conhecimento seja veiculado antes ou, ao menos, concomitante aos períodos iniciais do estágio curricular. Mas antes de analisarmos esse dado nas IES, cumpre observar que, no que tange ao debate de gênero na formação profissional, não são todos os cursos de Serviço Social das IES pesquisadas que oferecem essa discussão explicitamente, além de não apresentarem uma homogeneidade nos nomes conferidos às disciplinas. 
Quadro 4 - Nome da disciplina de gênero segundo IES

\begin{tabular}{|c|c|c|c|c|}
\hline Instituição & PUC-Rio & UERJ & UFF & UFRJ \\
\hline Nome da Disciplina & $\begin{array}{c}\text { Seminário de } \\
\text { Conteúdo Variável }\end{array}$ & $\begin{array}{c}\text { Relações Sociais de } \\
\text { Gênero e Etnia }\end{array}$ & $\begin{array}{c}\text { Relações de Gênero } \\
\text { e Questão Social }\end{array}$ & $\begin{array}{c}\text { A Questão de } \\
\text { Gênero no Brasil }\end{array}$ \\
\hline
\end{tabular}

Fonte: Coleta de Dados da Pesquisa, 2013.

Ressaltamos que no DSS/PUC-Rio não consta em sua grade curricular disciplina específica para o debate de gênero, porém existe "Seminário de Conteúdo Variável”, com ementa flexível, a qual poderá ser destinada ao debate das relações de gênero. Contudo, no período pesquisado só foi oferecida uma única vez com o tema "Violência doméstica: uma perspectiva de gênero", no segundo semestre de 2008.

A ESS/UFF aponta no título da disciplina uma leitura do gênero na articulação com a "questão social". Como vimos, esse é considerado o objeto de intervenção do Serviço Social a partir das discussões das Diretrizes Curriculares da Abepss. Já a ESS/UFRJ propõe uma descrição mais aberta do debate, contextualizando o gênero no Brasil. A FSS/UERJ indica em sua disciplina a articulação entre gênero e o debate das relações étnicas, o que se torna bastante complexo de se executar, tendo em vista a particularidade dos estudos nessas duas áreas, ainda que apresentem intersecções. Além disso, utiliza uma nomenclatura — "relações sociais de gênero" — que remete o debate às distinções teóricas presentes no campo dos estudos de gênero. ${ }^{9}$

No que se refere ao período em que a disciplina é oferecida, é importante observar que há uma proximidade com a entrada do aluno no campo de estágio. Esse fato é relevante, pois, como mencionamos, é nos espaços sócio-ocupacionais dos assistentes sociais que demandas de gênero podem ser visualizadas, o que vem corroborar o indício de que o profissional deve buscar fazer uma leitura da realidade do usuário não somente pelo viés econômico, mas também pelo de gênero. A leitura da realidade compreende a totalidade, razão pela qual é preciso "analisar com profundidade as contradições que se ocultam ou se fetichizam na realidade, superando a pseudoconcreticidade para propor uma intervenção que tenha alcance e efetividade" (Netto, 1997, vídeo).

9. Para essa referência, ver Kartchevsky-Bulport, 1986. 
Quadro 5 - Período da oferta das disciplinas de gênero segundo IES

\begin{tabular}{|c|c|c|c|c|}
\hline Instituição & PUC-Rio & UERJ & UFF & UFRJ \\
\hline Período & $6^{\circ}, 7^{\circ}$ ou $8^{\circ}$ & $4^{\circ}, 5^{\circ}$ ou $6^{\circ}$ & $\begin{array}{c}5^{\circ} \text { (diurno e } \\
\text { noturno) }\end{array}$ & $\begin{array}{c}4^{\circ} \text { (diurno) } \\
8^{\circ} \text { (noturno) }\end{array}$ \\
\hline
\end{tabular}

Fonte: Coleta de Dados da Pesquisa, 2013.

Aqui cabem algumas observações: já que o DSS/PUC-Rio não oferece uma disciplina específica, a disciplina "Seminário de Conteúdo Variável" é ofertada no $6^{\circ}, 7^{\circ}$ e $8^{\circ}$ períodos do curso; na ESS/UFRJ, no seu curso noturno, a disciplina "A Questão de Gênero no Brasil" é deslocada para a fase final do curso, perdendo a capacidade de instruir o olhar dos alunos no campo de estágio; na FSS/UERJ "Relações Sociais de Gênero e Etnia" aparece no $4^{\circ}, 5^{\circ}$ e $6^{\circ}$ períodos, por ser uma disciplina eletiva, conforme veremos a seguir.

Antes de apresentarmos o quadro que demonstra se a disciplina é ou não obrigatória no curso, cabe conceituar o que é disciplina obrigatória, eletiva e optativa. Para tanto, utilizaremos a definição do regulamento dos cursos de graduação da UFF. ${ }^{10}$

DISCIPLINAS/ATIVIDADES ELETIVAS - [...] de livre escolha do aluno, com o objetivo de ampliar a sua formação geral, [...] explicitado ou não no Currículo de cada Curso [...].

DISCIPLINAS/ATIVIDADES OBRIGATÓRIAS - [...] consideradas como imprescindiveis para a formação básica e profissional dos alunos, oriundas dos conteúdos de estudos discriminados nas diretrizes curriculares ou não, podendo ser de formação específica e/ou formação complementar.

DISCIPLINAS/ATIVIDADES OPTATIVAS - [...] visam a ampliar a formação profissional, de livre escolha do aluno, dentre um rol de disciplinas/atividades previamente determinadas e apresentadas no Currículo do Curso de Graduação [...]. (Proac, 2008, p. 4; grifos nossos)

10. Disponível em: $<$ http://www.proac.uff.br/files/RegulamentoAprovadoCEP.pdf $>$. Acesso em: 14 jul. 2014. 
Desse modo, podemos observar no quadro a seguir a relevância dada ao debate de gênero em cada uma das IES pesquisadas, a partir da modalidade que a disciplina adquire no currículo dos cursos.

Quadro 6 - Modalidade da disciplina Gênero segundo IES

\begin{tabular}{|c|c|c|c|c|}
\hline Instituição & PUC-Rio & UERJ & UFF & UFRJ \\
\hline Disciplina & Seminário & Eletiva & Obrigatória & Obrigatória \\
\hline
\end{tabular}

Fonte: Coleta de Dados da Pesquisa, 2013.

Observamos nos dados coletados que o curso de Serviço Social da FSS/UERJ é o único no qual a disciplina se caracteriza por ser uma eletiva, o que, como vimos nas definições anteriores, significa que o debate não é percebido como "imprescindível" à formação profissional, apenas visa "ampliar" esta. Apesar disso, verifica-se uma política departamental segundo a qual ela é ofertada todo semestre, sendo referenciada aos alunos do $4^{\circ}$ período. Esse dado nos mostra que na medida em que não são assegurados esses pactos no documento curricular, há grandes chances de que tais acordos se desfaçam, dependendo dos atores políticos e da direção do "jogo" no âmbito institucional, de modo que o debate de gênero pode inclusive deixar de existir na formação dos alunos. Obtivemos, contudo, a informação de que, na nova revisão curricular, essa situação foi alterada, e a disciplina passa a constar no quadro das obrigatórias. Entretanto, isso ocorre quase quinze anos após as demais unidades.

No DSS/PUC-Rio a disciplina "Seminário de Conteúdo Variável” compõe o Núcleo de Formação Profissional e visa proporcionar aos alunos conhecimentos teóricos no que tange à formação e à intervenção profissional. Assim, "na medida em que novas questões sociais surgem, elas são inseridas no currículo, por meio das disciplinas de Seminário de Conteúdo Variável” (PUC-Rio, 2002, p. 7).

Na ESS/UFRJ a disciplina “A Questão de Gênero no Brasil” é obrigatória. Além desse fato, observamos que existe outra disciplina, "Identidades Culturais e Serviço Social no Brasil", também obrigatória, com debate transversal ao tema, o qual envolve a formação racial da sociedade brasileira e seus mitos. Além dessas obrigatórias, encontramos, no período pesquisado, disciplina sobre a temática sen- 
do oferecida como eletiva, apresentando um leque mais abrangente de possibilidades de aprofundamento da matéria.

Na ESS/UFF, além da obrigatória "Relações de Gênero e Questão Social", encontramos a também obrigatória "Família, Políticas Sociais e Questão Social", que é transversal ao debate de gênero, na medida em que incorpora tendências de feminilização nas dinâmicas das famílias e da formulação das políticas sociais brasileiras. Foi interessante encontrar o debate de gênero na ementa da disciplina obrigatória “Acumulação Capitalista e Questão Social”.

Disciplina: Acumulação Capitalista e Questão Social. Ementa: Acumulação capitalista, Estado, luta de classes e a "questão social". O debate sobre a "questão social" na contemporaneidade: as perspectivas liberal, positivista e marxista. Formas de enfrentamento da "questão social" na ordem capitalista. Expressões culturais, étnico-raciais, geracionais e de gênero da "questão social" e sua vivência pelos sujeitos sociais. (UFF, 2010, p. 26; grifos nossos)

É importante ressaltar que a discussão de teorias de gênero pode estar presente em outras disciplinas, e não apenas naquelas cujos nomes explicitam a matéria, como mostra o exemplo acima. No caso da UERJ, como na UFF, isso aparece na disciplina de Classes Sociais, que também apresenta uma ementa que captura a possibilidade de uma leitura das classes integradas a outros marcadores sociais, como gênero e etnia. Entretanto, é imprescindível não perder de vista a questão de que há um "currículo oculto", operado na experiência docente na qual se efetiva a formação profissional, que nem sempre é representativo dos acordos textuais. Como qualifica Santomé em entrevista no Portal Aprendiz:

[...] de fato, a escola ensina muito mais [...]. Fundamentalmente são aprendizagens não intencionais, ou seja, que não estão no programa do professor de uma maneira expressa. São as consequências das cosmovisões e ideologias nas quais fomos educados e assumimos como "naturais", "óbvias" e "lógicas". Uma ideologia, quando se torna hegemônica, se plasma em determinadas práticas, rotinas, tradições, motivações e interesses que, de uma maneira consciente e reflexiva, nós não tratamos de trazer à luz, investigar, analisar e questionar. Esses tipos de tarefas que programamos e que cremos que são educativas, pois são partes do "senso comum", "sempre foram assim", "aprendi assim”, são as que seguem propondo os livros didáticos. (Santomé, 2013). 
Assim como o nome dado à disciplina de gênero aponta diferenciações, o mesmo ocorre no estudo do conteúdo das ementas. Como podemos notar na descrição seguinte, que apresenta as referências das matérias específicas de gênero em cada IES:

\section{Quadro 7 - Ementa da disciplina Gênero segundo IES}

\begin{tabular}{|c|c|}
\hline Instituição & Ementa \\
\hline PUC-Rio & $\begin{array}{l}\text { Disciplina: Seminário de Conteúdo Variável. } \\
\text { Ementa: Discussão das políticas sociais setoriais de temas atuais. Tema: "Violência doméstica: } \\
\text { uma perspectiva de gênero". }\end{array}$ \\
\hline UERJ & $\begin{array}{l}\text { Disciplina: Relações Sociais de Gênero e Etnia. } \\
\text { Ementa: a) Objetivo: Abordar as relações de gênero, geração e etnia numa perspectiva sócio- } \\
\text {-histórica e seus desdobramentos nas políticas públicas contemporâneas. b) Conteúdo: proble- } \\
\text { matização teórico-metodológica das temáticas enquanto categorias analíticas das práticas sociais } \\
\text { no campo político-cultural, onde interagem as dimensões socioeconômicas, de gênero, étnicas e } \\
\text { geracionais, constituindo hierarquias "legitimadas" por discursos opressores que desqualificam } \\
\text { as diferenças entre os grupos sociais. Assegurar o debate no campo dos direitos humanos e das } \\
\text { diversas políticas públicas, cuja importância vem sendo internacionalmente valorizada com base } \\
\text { no fortalecimento dos direitos. Apresentação de experiências tanto públicas (do Estado) como } \\
\text { privadas (organizações não governamentais) que atuam nos campos acima mencionados. }\end{array}$ \\
\hline UFF & $\begin{array}{l}\text { Disciplina: Relações de Gênero e Questão Social. } \\
\text { Ementa: Gênero: conceito e história. Gênero na ótica das relações de classe, etnia e geração no } \\
\text { enfrentamento da "questão social" na atualidade. O debate contemporâneo em torno do feminis- } \\
\text { mo, patriarcado, homossexualidades, masculinidades, etnicidade/racial. Gênero, proteção social } \\
\text { e Serviço Social. }\end{array}$ \\
\hline UFRJ & $\begin{array}{l}\text { Disciplina: A Questão de Gênero no Brasil. } \\
\text { Ementa: As teorias sobre gênero. Serviço Social e relações de gênero. Relações de gênero no } \\
\text { Brasil contemporâneo e expressões da questão social. }\end{array}$ \\
\hline
\end{tabular}

Fonte: Coleta de Dados da Pesquisa, 2013.

Apesar dos debates muito confluentes, podemos destacar que em algumas IES o conteúdo se estrutura em torno de uma apreensão teórica do conceito e de suas articulações com a "questão social", estabelecida como matéria central do trabalho do assistente social. Observamos, ainda, na ementa da disciplina da UERJ, uma ênfase nas expressões do debate no campo das políticas sociais, o que conflui para o eixo norteador da formação profissional nessa IES, definido em torno dessa área. Na disciplina da PUC-Rio, destaca-se a temática da violência como estruturante da 
ementa, o que se explica no contexto dessa IES pela existência, desde a década de 1990, de um trabalho de pesquisa e formação desenvolvido em torno dessa temática, vinculado à pós-graduação. ${ }^{11}$

É curioso observarmos que alguns marcadores sociais contemplados nas ementas das disciplinas, como geração, raça e etnia, são abrigados sob o mesmo "guarda-chuva" da disciplina de gênero em algumas IES, o que nos leva a suspeitar que mais do que um exercício de intersecção das categorias sociais, trata-se de um "espaço possível" destinado a um assunto ainda pouco visualizado como fundamento da formação profissional.

Tendo em vista a perspectiva sinalizada pela ESS da UFRJ, de considerar o gênero no campo da superação da sociedade burguesa e da emancipação humana, podemos pensar que a apreensão dos estudos de gênero no Serviço Social ocorra a partir da matriz crítica marxista, a qual hegemonicamente, na profissão, tem sido assimilada em sua perspectiva clássica. De modo que no campo dos estudos de gênero, tudo leva a crer que as teorias que investigam a categoria a partir de análises macrossociais, notadamente na dinâmica do trabalho, tendem a ser as que mais bem se coadunam com a cultura profissional.

O fato de desconsiderarmos o elemento cultural presente nos estudos de gênero pode nos levar a invisibilizar processos centrais para a efetivação da emancipação humana.

Os sinais aqui capturados evidenciam, a nosso ver, a incidência do debate de gênero no Serviço Social ao longo de sua trajetória profissional, mais marcadamente nas últimas décadas. Localizamos nesses indícios a busca por conexões entre o debate marxista e o de gênero na formação profissional, dentro da perspectiva hegemônica do Projeto Ético-Político no Serviço Social. Mesmo com pouco reconhecimento por parte das Diretrizes Curriculares, nas quais talvez a apreensão se torne mais lenta (curiosamente), o debate vai se disseminando.

11. Através de projetos vinculados a três linhas de pesquisa no período estudado: "Trabalho, Gênero e Políticas Sociais"; "Questões Socioambientais, Estudos Culturais e Desenvolvimento Sustentável"; "Violência, Família e Direitos Sociais". Essas linhas de pesquisa sofreram alteração em seus nomes e ementas a partir do ano de 2010, passando a ser denominadas: "Trabalho, Política Social e Sujeitos Coletivos"; "Questões Socioambientais, Urbanas e Forma de Resistência Social"; "Violência, Direitos, Serviço Social e Políticas Intersetoriais", respectivamente. 


\section{Considerações finais}

Ao realizarmos o debate sobre a formação profissional, pautado em uma análise das pistas e dos indícios dos estudos de gênero em currículos de cursos de Serviço Social de unidades reconhecidas, tanto pela qualidade quanto pela antiguidade deles, demonstramos que é ainda incipiente a apreensão desse aspecto como parte fundamental da experiência de sociabilidade dos sujeitos na sociedade capitalista, bem como do projeto de emancipação humana no discurso profissional.

Além desse aspecto, por ser a profissão, desde sua origem, majoritariamente feminina e ligada ao "cuidado", deve-se considerar que o debate de gênero seja necessário na formação de assistentes sociais. Ao analisarmos os currículos das quatro IES estudadas, percebemos que cada uma delas incorpora o debate de forma diferente, embora o núcleo comum consista no lugar secundário que o debate ocupa na formação profissional.

Entretanto, a pesquisa nos surpreendeu ao indicar um conjunto de eventos que de uma perspectiva do paradigma indiciário aponta um crescente envolvimento profissional com os estudos de gênero. A partir de então passamos a formular a hipótese de que os cenários sócio-ocupacionais do Serviço Social na atualidade, marcados por políticas sociais setorializadas, fragmentadas e de cunho feminilista e familista, impactam o exercício profissional e, mais lentamente, a formação dos assistentes sociais.

Recebido em 24/1/2016 - Aprovado em 7/3/2016

\section{Referências bibliográficas}

ASSOCIAÇÃO BRASILEIRA DE ENSINO E PESQUISA EM SERVIÇO SOCIAL (ABEPSS). Diretrizes gerais para o curso de Serviço Social. Rio de Janeiro, nov. 1996. Disponível em: $<$ http://www.abepss.org.br/files/Lei_de_Diretrizes_Curriculares_1996.pdf> Acesso em: 5 out. 2013.

GINZBURG, C. Mitos, emblemas, sinais: morfologia e história. São Paulo: Companhia das Letras, 1990. 
GINZBURG, C. Nenhuma ilha é uma ilha: quatro visões da literatura inglesa. São Paulo: Companhia das Letras, 2004.

KARTCHEVSKY-BULPORT, A. et al. O sexo do trabalho. Rio de Janeiro: Paz e Terra, 1986.

NETTO, J. P. Encontro nacional de assistentes sociais. Palestra em vídeo. CFESS, nov. 1997.

OLIVEIRA, I. M.; MOREIRA, M. R. A.; GURGEL, T. Editorial. Temporalis, Brasília, v. 1, n. 27, p. 9-10, jan./jun. 2014.

PONTIFÍCIA UNIVERSIDADE CATÓLICA DO RIO DE JANEIRO (PUC-RIO). Departamento de Serviço Social. Projeto Pedagógico de Curso (PPC). Rio de Janeiro, jul. 2002. PRÓ-REITORIA ACADÊMICA (PROAC). Regulamento dos cursos de graduação. Universidade Federal Fluminense (UFF). Niterói, nov. 2008. Disponível em: < http://www. proac.uff.br/files/RegulamentoAprovadoCEP.pdf>. Acesso em: 14 jul. 2014.

SANTOMÉ, J. T. El curriculum oculto. 8. ed. Madri: Morata, 2005.

. Professor espanhol aponta "sentidos ocultos" na educação. Entrevistador: Pedro Ribeiro Nogueira, 5 set. 2013. Disponível em: < http://portal.aprendiz.uol.com.br/2013/09/05/ jurjo-torres-educar-e-gerar-sonhos/>. Acesso em: 7 ago. 2014.

SILVA, S. K.; DELBONI, T. M. Z. G. F. O currículo integrado como campo possível de invenção de mundos plurais emancipatórios: uma conversa com Jurjo Torres Santomé. Revista Teias, Rio de Janeiro, v. 13, n. 27, p. 279-286, jan./abr. 2012.

TEMPORALIS. Serviço Social, relações de exploração/opressão de gênero, raça/etnia, geração, sexualidades. Brasília, v. 1, n. 27, jan./jun. 2014.

UNIVERSIDADE DO ESTADO DO RIO DE JANEIRO (UERJ). Faculdade de Serviço Social. Currículo Pleno — Curso de Graduação em Serviço Social. Rio de Janeiro, out. 1992.

UNIVERSIDADE FEDERAL DO RIO DE JANEIRO (UFRJ). Escola de Serviço Social. Currículo Pleno - Curso de Graduação em Serviço Social. Rio de Janeiro, maio 2001.

UNIVERSIDADE FEDERAL FLUMINENSE (UFF). Escola de Serviço Social. Projeto Pedagógico de Curso (PPC). Niterói, maio 2010. 